\title{
Genetic diversity of Bletilla striata assessed by SCOT and IRAP markers
}

Yan Guo ${ }^{1 \dagger}$, Lina Zhai ${ }^{1 \dagger}$, Hao Long ${ }^{1}$, Nipi Chen ${ }^{1}$, Chengxian Gao ${ }^{1}$, Zhishan Ding ${ }^{2}$ and Bo Jin ${ }^{1 *}$ (D

\begin{abstract}
Background: Bletilla striata is a well-known traditional Chinese herb with varieties of functions. In China, the natural resources of Bletilla striata have been severely damaged because of the excessive exploitation and destruction of natural habitats. The aim of present study was to provide a reference for fully exploiting and utilizing the germplasm resources of Bletilla striata.

Results: The genetic diversity of 50 varieties of Bletilla striata from different area in China was analyzed by SCoT and IRAP molecular marker technique. A total of 209 bands were amplified by 20 groups of SCoT primers, of which 201 (96.17\%) were polymorphic, and 47 polymorphic bands (94\%) were observed in 50 bands amplified by 8 groups of IRAP primers. The 50 populations of Bletilla striata were divided into two major groups by SCOT and IRAP at the genetic similarity coefficient value of 0.60 and 0.68 individually. The partition of clusters in the unweighted pair group method with arithmetic mean dendrogram and principal coordinate analysis plot based on the SCOT and IRAP markers was similar.
\end{abstract}

Conclusions: Results indicated the abundant genetic diversity of Bletilla striata among different areas. Our results will provide useful information for resource protection.

Keywords: Bletilla striata, Genetic diversity, SCOT, IRAP, Cluster analysis

\section{Background}

Bletilla striata is a well-known traditional Chinese herb, which was first described in Shennong BenCao Jing (Shennong's Materia Medica) 2000 years ago. In China, there are four unique populations: Bletilla striata, Bletilla formosana, Bletilla ochracea and Bletilla sinensis [20]. Traditional Chinese Medicine holds that Bletilla striata is capable of restraining blood leakage, stopping bleeding, dispersing swelling and promoting tissue regeneration. Thus it could be effectively applied in the treatment of hematemesis, hemoptysis, traumatic bleeding, chapped kin, and ulcerative carbuncle $[4,17]$. Besides, Bletilla striata can be added in medicated diets or drinks when stewed together with chicken or duck and extracted by boiling water or brewed as wine material [14]. Additionally, the non-medical uses of Bletilla striata include rubbing its mucilaginous roots in inkstones

\footnotetext{
* Correspondence: jinbo@zcmu.edu.cn

†Yan Guo and Lina Zhai contributed equally to this work

${ }^{1}$ College of Life Science, Zhejiang Chinese Medical University, Hangzhou

310053, China

Full list of author information is available at the end of the article
}

with vermilion for writing [7], and another use is as an insecticide [12]. In industry, Bletilla extract is used as a coating agent and cosmetic additive [14]. Moreover, the plant also has very high decorative value [14]. The wide uses of Bletilla striata results in demand exceeding supply.

In China, the natural resources of Bletilla striata have been severely damaged because of the excessive exploitation and destruction of natural habitats [14]. More than 10 years ago, Bletilla striata was listed as one of the key protected wild medicinal plants (http://rep.iplant.cn/). The price of Bletilla striata has soared 20-fold in the past 10 years [14]. In order to solve the problem of Bletilla striata resources, the artificial cultivation of Bletilla striata and its related species has been developed in the majority of regions in China [9]. More importantly, research on strengthening the selection and breeding of excellent varieties of Bletilla striata also has been launched [22]. As part of the efforts to protect the precious plant and explore the best way to utilize the entire plant, our laboratory established good practice for the genetic relationships of Bletilla until now. 
Molecular markers are one of the most important methods to allow cultivar identification. They are widespread used on account of their simple operation and high detection efficiency [8]. The different DNA-based molecular markers unfold plant variability directly at genetic levels with reliable data required for the estimation of genetic diversity [2], such as inter-simple sequence repeats (ISSR), inter-retrotransposon amplified polymorphism (IRAP), or start codon targeted (SCoT) polymorphism [13]. In this investigation, SCoT and IRAP were used to assess genetic constancy of Bletilla striata.

The objectives of this study are to investigate the genetic relationships among some Bletilla striata species in China and construct a molecular phylogenetic tree, which provides a theoretical basis for protection, selection and development.

\section{Results}

The oligo nucleotide sequences of SCoT and IRAP primers are summarized in Table 1.

\section{Genetic diversity revealed by SCOT polymorphic markers}

Twenty groups of primers were used to detect genetic polymorphisms in the samples. The primers produced 209 clear SCoT bands, including 201 polymorphism bands. The total number of scored bands varied from 6 (for SC8 + SC11) to 14 (for SC16+SC21, SC17 + SC20) with an average of 10.5 bands per primer (Table 2). The number of the polymorphic bands ranging from 6 (for $\mathrm{SC} 8+\mathrm{SC} 11$ ) to 13 (for $\mathrm{SC} 16+\mathrm{SC} 21, \mathrm{SC} 17+\mathrm{SC} 20$,
SC14 + SC23) with a mean of $96.17 \%$ was polymorphic bands per primer (Table 2). The PIC value was ranging from 0.92 to 0.99 , with a mean value of 0.96 , indicated that the SCoT primers used in the study were effective and polymorphic (Table 2). The Nei's index varied from 0.28 (for SC18 + SC19) to 0.42 (for SC14 + SC33) with a mean value of 0.37 (Table 2). A dendrogram (Fig. 1) was constructed based on the similarity matrix (data not shown). The highest genetic similarity coefficient $(0.87)$ was found between 38 and 39 . With a genetic similarity coefficient value of 0.60 , the 50 varieties were divided into two major groups. Group I included twenty-five varieties; the all other varieties were classified into Group II. And the results of cophenetic correlation analysis are shown below (Fig. 2) (the correlation coefficient is $r=0.752$, indicating that the clustering results are good).

\section{Genetic diversity revealed by IRAP polymorphic markers}

Eight groups of primers were used to detect genetic polymorphisms in the samples. The primers produced 50 clear IRAP bands, including 47 polymorphism bands. The total number of scored bands varied from 4 (for LIRE-Tar-F + LIRE-del-F1) to 9 (for DO-F + LIRE-del-F1) with an average of 6.3 bands per primer (Table 2). The number of the polymorphic bands ranging from 4 (for LIRE-Tar-F + LIRE-del-F1) to 8 (for DO-F + LIRE-del-F1) with a mean of $94 \%$ was polymorphic bands per primer (Table 2). The PIC value was ranging from 0.85 to 0.98 , with a mean value of 0.93 , indicated that the IRAP primers used in the

Table 1 All molecular marker primers sequence of SCOT and IRAP used in this research

\begin{tabular}{|c|c|c|c|c|c|}
\hline \multicolumn{3}{|c|}{$\underline{\text { SCOT primer }}$} & \multirow[b]{2}{*}{ Sequence $\left(5^{\prime}\right.$ to $\left.3^{\prime}\right)$} & \multicolumn{2}{|l|}{ IRAP primer } \\
\hline Code & Sequence(5'to3') & Code & & Code & Sequence( $5^{\prime}$ to $\left.3^{\prime}\right)$ \\
\hline SC3 & CAACAATGGCTACCACCG & SC19 & ACCATGGCTACCACCGGC & LIRE3-F & ССTCAAAGCTCTCTTCTCCTTC \\
\hline SC4 & CAACAATGGCTACCACCT & SC20 & ACCATGGCTACCACCGCG & LIRE3-R & CCTAGAGTTGTACATTTACATT \\
\hline SC5 & CAACAATGGCTACCACGA & SC21 & ACGACATGGCGACCCACA & LIRE-Tar-F & CATYATCRGTGGAGCTCT \\
\hline SC6 & CAACAATGGCTACCACGC & SC22 & AACCATGGCTACCACCAC & LIRE-Tar-R & AATCATYYYGAGAGCTCTCC \\
\hline SC7 & CAACAATGGCTACCACGG & SC23 & CACCATGGCTACCACCAG & LIRE-del-F1 & TTGAAACCACYAGCTCAAGGTA \\
\hline SC9 & CAACAATGGCTACCAGCA & SC24 & CACCATGGCTACCACCAT & LIRE-del-F2 & TATAAAATGTCRGGTCGTGA \\
\hline SC10 & CAACAATGGCTACCAGCC & SC25 & ACCATGGCTACCACCGGG & LIRE-del-R & TCATGRAGRTGATARAGWYTAACC \\
\hline SC11 & AAGCAATGGCTACCACCA & SC26 & ACCATGGCTACCACCGTC & DO-F & TCCACAAGGCTATCTATG \\
\hline SC12 & ACGACATGGCGACCAACG & SC27 & ACCATGGCTACCACCGTG & DO-R & GAGGGATTGGACTTACTG \\
\hline SC13 & ACGACATGGCGACCATCG & SC28 & CCATGGCTACCACCGCCA & & \\
\hline SC14 & ACGACATGGCGACCACGC & SC30 & CCATGGCTACCACCGGCG & & \\
\hline SC15 & ACGACATGGCGACCGCGA & SC31 & CCATGGCTACCACCGCCT & & \\
\hline SC16 & ACCATGGCTACCACCGAC & SC32 & CCATGGCTACCACCGCAC & & \\
\hline SC17 & ACCATGGCTACCACCGAG & SC33 & CCATGGCTACCACCGCAG & & \\
\hline SC18 & ACCATGGCTACCACCGCC & SC34 & ACCATGGCTACCACCGCA & & \\
\hline
\end{tabular}


Table 2 Characteristics of SCOT and IRAP banding profiles produced in the studied Bletilla striata

\begin{tabular}{lllllll}
\hline Primer name & TB & PB & PP(\%) & PIC & Nei's & Fst \\
\hline IRAP & 7 & 5 & 71.43 & 0.87 & 0.45 & 0.009 \\
Do-F + tar-R & 5 & 5 & 100 & 0.94 & 0.40 & 0.018 \\
DO-F + LIRE-del-F2 & 9 & 8 & 88.89 & 0.96 & 0.23 & 0.012 \\
DO-F + LIRE-del-F1 & 9 & & & & & \\
LIRE-del-F1 + LIRE-Tar-R & 7 & 7 & 100 & 0.98 & 0.35 & 0.023 \\
LIRE3-R + LIRE-del-R & 6 & 6 & 100 & 0.95 & 0.25 & 0.011 \\
LIRE3-R + LIRE-TAR-R & 6 & 6 & 100 & 0.97 & 0.36 & 0.023 \\
LIRE3R + DO-R & 6 & 6 & 100 & 0.91 & 0.38 & 0.019 \\
LIRE-Tar-F + LIRE-del-F1 & 4 & 4 & 100 & 0.85 & 0.42 & 0.012
\end{tabular}

Total

\begin{tabular}{|c|c|c|c|c|c|c|}
\hline Mean & 50 & 47 & & & & \\
\hline SCOT & 6.25 & 5.88 & 95.04 & 0.93 & 0.36 & 0.016 \\
\hline $\mathrm{SC} 17+\mathrm{SC} 30$ & 10 & 10 & 100 & 0.98 & 0.36 & 0.007 \\
\hline $\mathrm{SC} 5+\mathrm{SC} 14$ & 11 & 11 & 100 & 0.97 & 0.42 & 0.009 \\
\hline $\mathrm{SC} 8+\mathrm{SC} 11$ & 6 & 6 & 100 & 0.92 & 0.39 & 0.012 \\
\hline SC14 + SC33 & 10 & 9 & 90 & 0.93 & 0.42 & 0.016 \\
\hline $\mathrm{SC} 15+\mathrm{SC} 32$ & 11 & 11 & 100 & 0.97 & 0.33 & 0.016 \\
\hline $\mathrm{SC} 16+\mathrm{SC} 21$ & 14 & 13 & 92.86 & 0.96 & 0.41 & 0.015 \\
\hline $\mathrm{SC} 17+\mathrm{SC} 20$ & 14 & 13 & 92.86 & 0.92 & 0.33 & 0.013 \\
\hline SC18 + SC19 & 12 & 11 & 91.67 & 0.97 & 0.28 & 0.017 \\
\hline $\mathrm{SC} 3+\mathrm{SC} 34$ & 7 & 7 & 100 & 0.94 & 0.34 & 0.021 \\
\hline $\mathrm{SC} 4+\mathrm{SC} 33$ & 9 & 8 & 88.89 & 0.94 & 0.39 & 0.023 \\
\hline $\mathrm{SC} 5+\mathrm{SC} 32$ & 10 & 9 & 90 & 0.97 & 0.38 & 0.017 \\
\hline SC6 + SC31 & 10 & 10 & 100 & 0.98 & 0.35 & 0.019 \\
\hline $\mathrm{SC} 7+\mathrm{SC} 30$ & 9 & 9 & 100 & 0.98 & 0.41 & 0.017 \\
\hline $\mathrm{C} 9+\mathrm{SC} 28$ & 10 & 9 & 90 & 0.98 & 0.33 & 0.015 \\
\hline $\mathrm{SC} 10+\mathrm{SC} 27$ & 12 & 12 & 100 & 0.96 & 0.39 & 0.017 \\
\hline$=11+$ SC26 & 10 & 10 & 100 & 0.96 & 0.29 & 0.016 \\
\hline $\mathrm{SC} 12+\mathrm{SC} 25$ & 12 & 11 & 91.67 & 0.95 & 0.38 & 0.019 \\
\hline$-13+$ SC24 & 8 & 8 & 100 & 0.99 & 0.37 & 0.021 \\
\hline $14+$ SC23 & 13 & 13 & 100 & 0.99 & 0.34 & 0.023 \\
\hline $15+$ SC22 & 11 & 11 & 100 & 0.93 & 0.36 & 0.021 \\
\hline al & 209 & 201 & & & & \\
\hline an & 10.45 & 10.05 & 96.40 & 0.96 & 0.37 & 0.017 \\
\hline
\end{tabular}

Abbreviation: TB Total bands, PB Polymorphic bands, $p p$ Polymorphic percentage, PIC Polymorphic Information Content, Fst Differentiation between populations index

study were effective and polymorphic (Table 2). The Nei's index varied from 0.23 (for DO-F + LIRE-del-F1) to 0.43 (for Do-F + tar-R) with a mean value of 0.36 (Table 2). A dendrogram (Fig. 3) was constructed based on the similarity matrix (data not shown). The highest genetic similarity coefficient (0.94) was found between 12, 26, 32 and 38 . With a genetic similarity coefficient value of 0.78 , the 50 varieties were divided into two major groups. Group I included two varieties: 19 and 42; the all other varieties were classified into Group II. And the results of cophenetic correlation analysis are shown below (Fig. 4) (the correlation coefficient is $r=0.707$, indicating that the clustering results are good).

\section{Analysis of PCoA}

PCoA analysis was done to see the displacement of the accessions and to further confirm the clustering pattern obtained from the dendrogram. The result of the three-dimensional (3D) plots of $\mathrm{PCoA}$ analysis for SCoT marker analysis was also similar to that of clustering in the dendrogram (Fig. 5). PCoA analysis indicated the first three axes accounted for $26.2 \%$ of total variation among all the accessions studied. The first, second and third axes represented 12.9, 7.2 and 6.1\% of the variation respectively. The result of the three-dimensional (3D) plots of PCoA analysis for IRAP marker analysis was similar to that of clustering in the dendrogram (Fig. 6). PCoA analysis indicated the first three axes accounted for $30.4 \%$ of total variation among all the accessions studied. The first, second and third axes represented 11.7, 10.9 and $7.8 \%$ of the variation respectively.

\section{Analysis of molecular variance (AMOVA)}

The analysis of molecular variance (AMOVA) of the SCoT data revealed that out of the total recorded variation, $79.38 \%$ was recorded within the species level whereas $20.62 \%$ was compartmentalized amongst the species. Similar in distribution to that of SCoT, IRAP marker data accounted for $77.36 \%$ variability at inter-specific level and $22.64 \%$ at intra-specific level. Which indicated high genetic variation within populations, and using SCoT marker reveled higher variation within and among populations of Bletilla striata (Table 3).

\section{Discussion}

In general, the genetic characteristics of a species are affected primarily by various ecological and biological traits, modes of reproduction and breeding and also by the various human mediated anthropogenic activities (Hamrick and Godt 1996; Nybom 2004). The genetic background of wild Bletilla striata becomes complex because of prolonged cross pollination and natural selection. In this study, we collected a variety of Bletilla striata from China. The genetic diversity and phylogenetic relationships of the samples were analyzed using SCoT and IRAP markers. The SCoT marker systems are proved to be efficient and inexpensive ways to provide molecular data to assess 


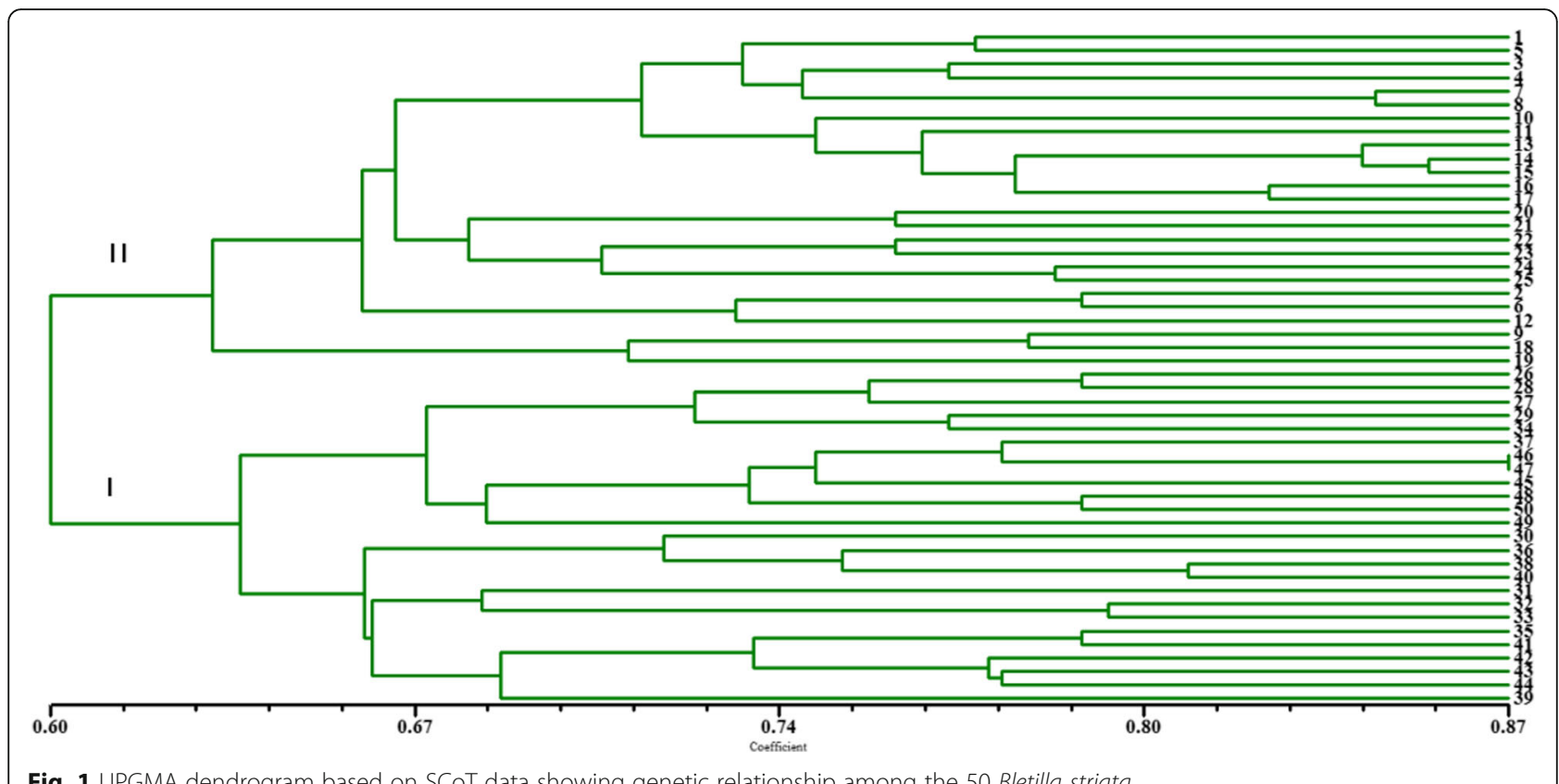

Fig. 1 UPGMA dendrogram based on SCOT data showing genetic relationship among the 50 Bletilla striata

genetic diversity, and it has been used successfully to determine genetic relationships for many plants ([15]; Bhattacharyya et al. 2013; [21]) whereby primers target the short-conserved region flanking the ATG translation start codon of plant genes [5]. IRAP is developed by Kalendar et al. [6] and initially designed to identify different barley $(H$. vulgare $)$ cultivars. IRAP markers involve the PCR amplification of DNA sequences between two nearby retrotransposons, using a primer designed from the LTR sequence of a retrotransposon, which were recently used extensively in studying genetic diversity, genetic relationship and germplasm management $[15,21]$. In the ATG flanking region, 20 groups of SCoT primers obtained a ratio

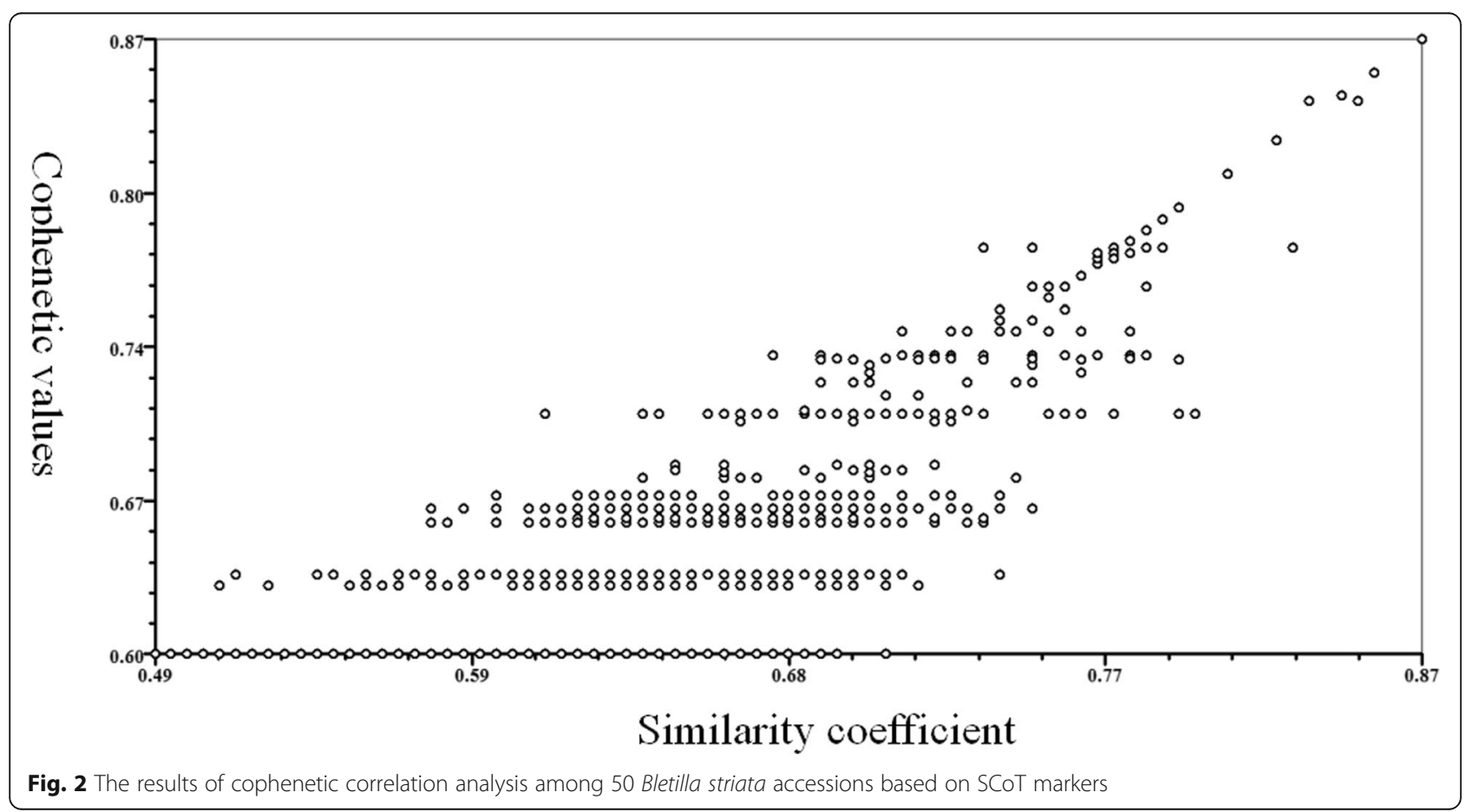




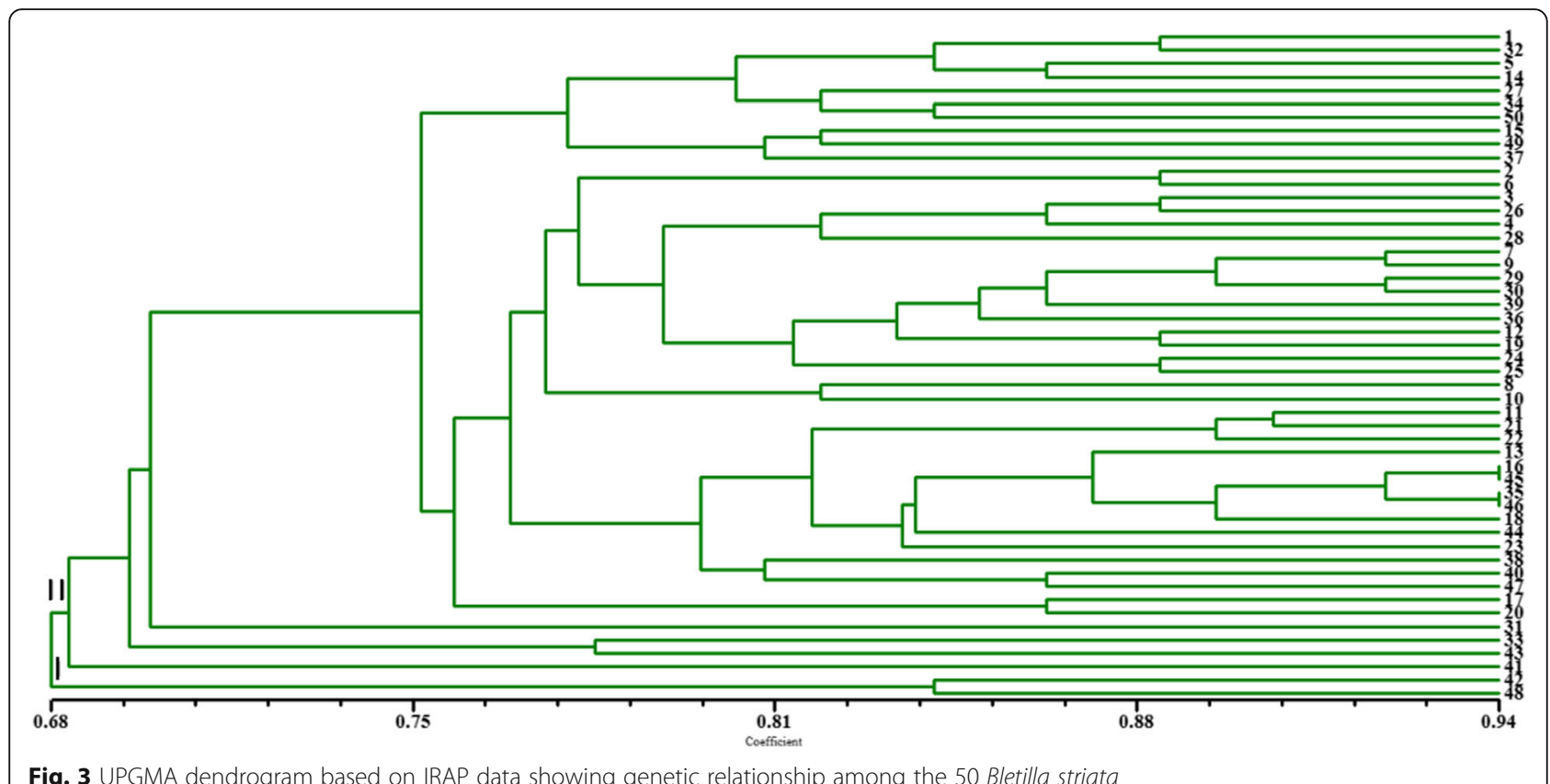

Fig. 3 UPGMA dendrogram based on IRAP data showing genetic relationship among the 50 Bletilla striata

of $96.17 \%$ polymorphism. In the LTR region, 8 groups of IRAP primer combinations of polymorphic fragments obtained a ratio of $94 \%$. The results indicated that both the SCoT and IRAP markers are equally efficient in the detection of polymorphism. However, SCoT proved to have slightly higher detection capacity i.e. in comparison to IRAP.
Sometimes, making use of only one marker for evaluating the genetic diversities among species may ignore a lot of unanswered questions [18]. However, combining polymorphic information derived from different marker systems was expected to decrease the effects of their independent inaccuracies [11]. Genetic relationship evaluation using a combination of SCoT+IRAP would result

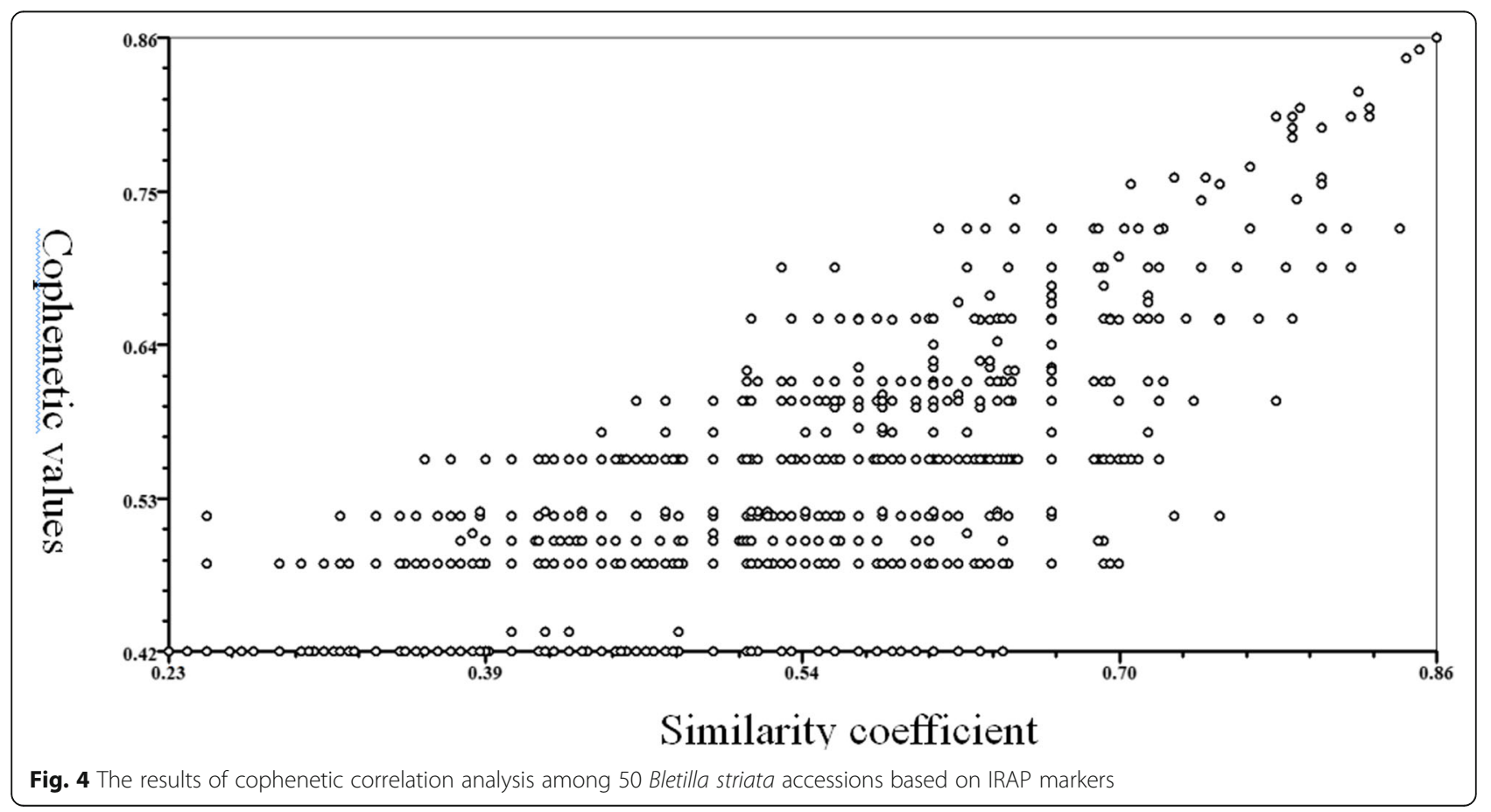




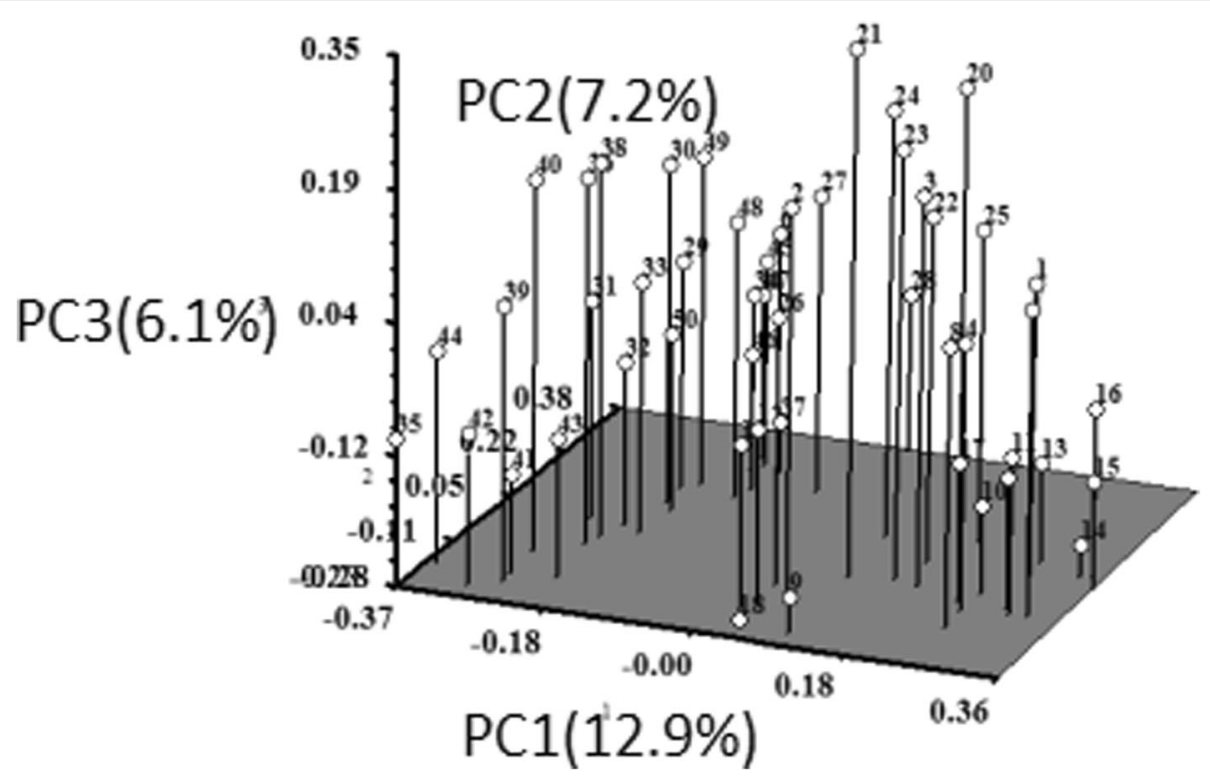

Fig. 5 Three-dimensional plots of PCoA indicating relationships among 50 Bletilla striata accessions based on SCoT markers

in a more accurate and reliable analysis of genetic diversities compared with a single marker. Our report is the first to integrate SCoT and IRAP data to elucidate the genetic relationships among Bletilla species, which can serve as a basis for the establishment of an effective system for species identification and genetic diversity analysis of Bletilla striata.
The UPGMA dendrograms indicated the abundant genetic diversity of the samples. Bletilla striata collected from one province can be clustered into nearly 2 clusters. The genetic distances of Bletilla striata from different provinces can be very close regardless of the flowers' color. Therefore, combining the current status of online trade prevalence, we suspect that exchanging universally

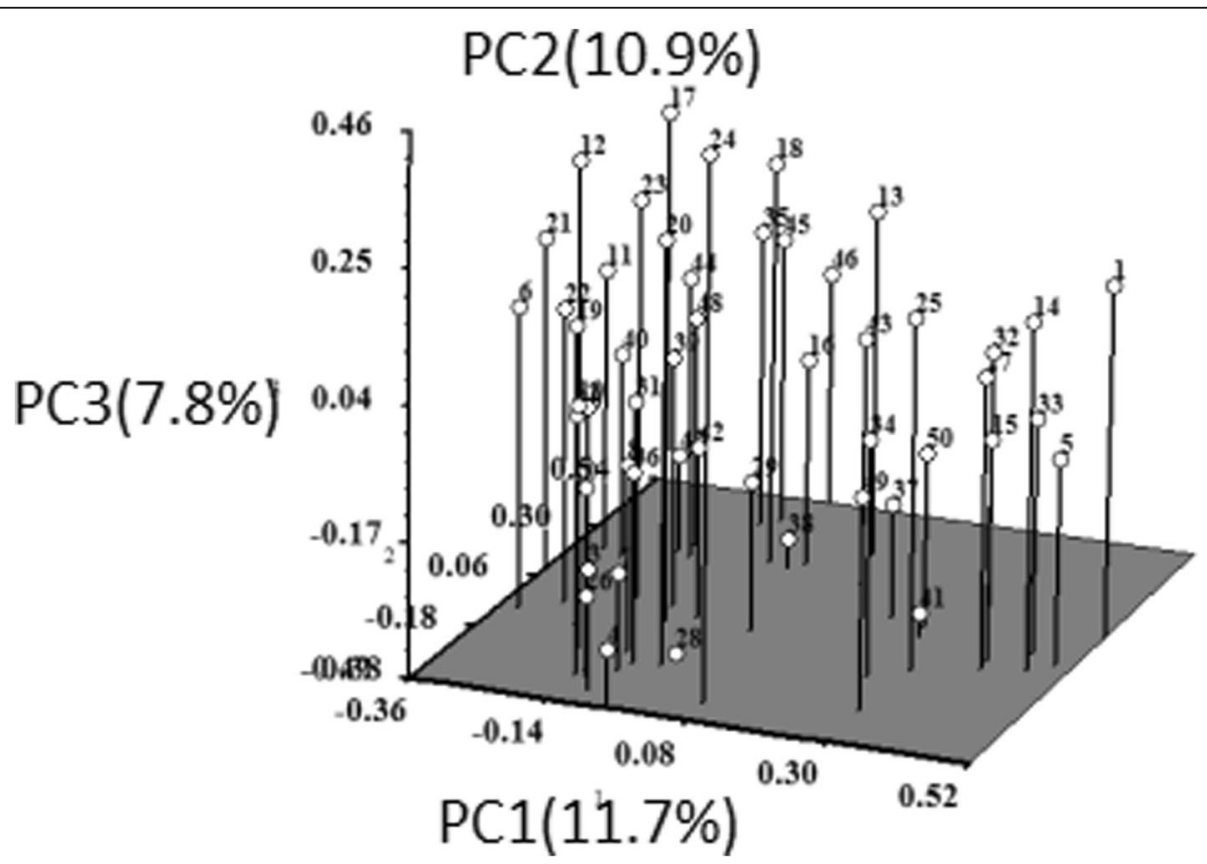

Fig. 6 Three-dimensional plots of PCOA indicating relationships among 50 Bletilla striata accessions based on IRAP markers 
Table 3 Analysis of molecular variance (AMOVA) among and within species based on SCOT marker (a) and IRAP marker (b)

\begin{tabular}{|c|c|c|c|c|c|}
\hline Source of variation & $\mathrm{df}$ & $\begin{array}{l}\text { Sum of } \\
\text { squares }\end{array}$ & $\begin{array}{l}\text { Variance } \\
\text { components }\end{array}$ & Variation (\%) & $P$-value \\
\hline \multicolumn{6}{|l|}{ a } \\
\hline Among populations & 3 & 385.11 & 1.87054 & 20.62 & $P<0.001$ \\
\hline Within populations & 46 & 783.35 & 21.3307 & 79.38 & $P<0.001$ \\
\hline Total & 49 & 2049.35 & 23.52211 & & \\
\hline \multicolumn{6}{|l|}{$b$} \\
\hline Among populations & 3 & 365.49 & 2.66702 & 22.64 & $P<0.001$ \\
\hline Within populations & 46 & 667.90 & 27.3087 & 77.36 & $P<0.001$ \\
\hline Total & 49 & 1329.72 & 30.41602 & & \\
\hline
\end{tabular}

results in the serious situation of transplanting and cross planting, which may cause high genetic variation among the populations from different areas. At the same time, we found that Bletilla striata collected from the same province are also far apart. The reason for this separation can be its growth background. Bletilla striata from different region may change the genetic information due to the hybridization between different parental, with the coaction of the effect of the soil, nutrients, temperature, and moisture resulting in differences in genetic traits, making the genetic diversity of Bletilla striata from the same area more complicated. Furthermore, the UPGMA clustering indicated that there was no significant relationship between genetic and geographic distances. This result was confirmed by the PCoA which indicates that the geographical distribution is not the main factor that shaped the current population genetic structure. For those populations with high levels of genetic variation of different regions, we suggest that their habitats should be protected and the exploitation of wild resources be controlled.

Experiments have shown that the genetic relationships among different geographical origins of Bletilla striata are complex. As a valuable Chinese herbal medicine, to protect and take artificial breeding of wild resources are very important. We hope that this research provides some references and theoretical basis for the identification and selection of good seeds of Bletilla striata resources.

\section{Conclusions}

The primary objective in nature conservation is to preserve the evolutionary potential of species through maintaining as much genetic diversity as possible. Thus, knowledge of the genetic variation between and within different populations of plant species plays a significant role in the formulation of appropriate strategies for their conservation [10]. In summary, our study revealed that 50 samples of Bletilla striata depicted a high level of genetic diversity. SCoT and IRAP markers can provide highly accurate and efficient information on population genetic diversity. This study provides valuable baseline data on the population genetics of Bletilla striata from China, which is useful for germplasm appraisal and resource protection, including the construction of a core collection and regional variety distribution and subrogation. Finally, it is noted that the agarose gel electrophoresis detection is simple and easy to operate, but it is often difficult to get a clear, easily distinguishable photo. Even a large number of repeated tests are required to meet the final test requirements. Capillary electrophoresis may be used in the future to obtain more accurate analysis results.

\section{Material and methods \\ Materials}

The Bletilla striata collected in this experiment were identified by professor Zhishan Ding of Zhejiang Chinese Medical University. A voucher specimen of the plant material used in this study has been deposited in molecular biology laboratory of Zhejiang Chinese Medical University (From NO.BJ-20160301-001 to NO.BJ20160301-050). Specific information is in Table 4, Fig. 7.

\section{Leaf DNA extraction}

A modified cetyltrimethyl ammonium bromide (CTAB) method was used for DNA extraction [21]. DNA samples were stored at $-20{ }^{\circ} \mathrm{C}$ and the quality verified by electrophoresis on ethidium bromide stained $1 \%$ agarose gel.

\section{Determination of IRAP and SCOT systems}

Karim Sorkheh et al. used IRAP for germplasm analysis of wild Pistacia chinensis [16], and Ahmad Mousapour Gorji et al. used SCoT to analyze the genetic fingerprint of tetraploid potatoes [1]. We used $20 \mu \mathrm{L}$ of the IRAP and SCoT molecular markers in both studies. 
Table 4 Sources and description of materials

\begin{tabular}{|c|c|c|c|}
\hline No & Location & Species name & Flower color \\
\hline 1 & Hubei Province, China & Bletilla striata & Purple \\
\hline 2 & Hubei Province, China & Bretilla sinensis & White \\
\hline 3 & Hubei Province, China & Bletilla striata & Purple \\
\hline 4 & Hubei Province, China & Bletilla ochracea & Yellow \\
\hline 5 & Hubei Province, China & Bletilla striata & Purple \\
\hline 6 & Hubei Province, China & Bletilla striata & Purple \\
\hline 7 & Hubei Province, China & Bletilla striata & Purple \\
\hline 8 & Hubei Province, China & Bletilla striata & Purple \\
\hline 9 & Hubei Province, China & Bretilla sinensis & White \\
\hline 10 & Hubei Province, China & Bletilla striata & Purple \\
\hline 11 & Hubei Province, China & Bletilla striata & Purple \\
\hline 12 & Hubei Province, China & Bretilla sinensis & White \\
\hline 13 & Hubei Province, China & Bletilla striata & Purple \\
\hline 14 & Hubei Province, China & Bletilla striata & Purple \\
\hline 15 & Anhui Province, China & Bletilla striata & Purple \\
\hline 16 & Anhui Province, China & Bletilla striata & Purple \\
\hline 17 & Anhui Province, China & Bletilla striata & Purple \\
\hline 18 & Anhui Province, China & Bletilla striata & Purple \\
\hline 19 & Anhui Province, China & Bletilla striata & Purple \\
\hline 20 & Anhui Province, China & Bletilla striata & Purple \\
\hline 21 & Sichuan Province, China & Bletilla striata & Purple \\
\hline 22 & Sichuan Province, China & Bletilla striata & Purple \\
\hline 23 & Sichuan Province, China & Bletilla striata & Purple \\
\hline 24 & Sichuan Province, China & Bretilla sinensis & White \\
\hline 25 & Henan Province, China & Bletilla striata & Purple \\
\hline 26 & Henan Province, China & Bletilla striata & Purple \\
\hline 27 & Henan Province, China & Bletilla striata & Purple \\
\hline 28 & Guizhou Province, China & Bletilla striata & Purple \\
\hline 29 & Guizhou Province, China & Bletilla striata & Purple \\
\hline 30 & Yunnan Province, China & Bletilla striata & Purple \\
\hline 31 & Yunnan Province, China & Bletilla striata & Purple \\
\hline 32 & Yunnan Province, China & Bletilla striata & Purple \\
\hline 33 & Zhejiang Province, China & Bletilla striata & Purple \\
\hline 34 & Zhejiang Province, China & Bletilla striata & Purple \\
\hline 35 & Zhejiang Province, China & Bletilla striata & Purple \\
\hline 36 & Zhejiang Province, China & Bletilla striata & Purple \\
\hline 37 & Zhejiang Province, China & Bletilla striata & Purple \\
\hline 38 & Zhejiang Province, China & Bletilla striata & Purple \\
\hline 39 & Zhejiang Province, China & Bletilla striata & Purple \\
\hline 40 & Shanxi Province, China & Bletilla striata & Purple \\
\hline 41 & Shanxi Province, China & Bretilla sinensis & White \\
\hline 42 & Shanxi Province, China & Bletilla striata & Purple \\
\hline 43 & Shanxi Province, China & Bletilla striata & Purple \\
\hline 44 & Shanxi Province, China & Bletilla striata & Purple \\
\hline
\end{tabular}

Table 4 Sources and description of materials (Continued)

\begin{tabular}{llll}
\hline No & Location & Species name & Flower color \\
\hline 45 & Gansu Province, China & Bletilla striata & Purple \\
46 & Hunan Province, China & Bletilla striata & Purple \\
47 & Fujian Province, China & Bletilla striata & Purple \\
48 & Jiangxi Province, China & Bletilla striata & Purple \\
49 & Jiangxi Province, China & Bletilla striata & Purple \\
50 & Guangxi Province, China & Bletilla striata & Purple \\
\hline
\end{tabular}

\section{SCoT analysis}

PCR amplification was performed in a final reaction volume of $20 \mu \mathrm{L}$ containing $10 \times$ buffer, $0.1 \mathrm{mM}$ dNTPs, $0.3 \mu \mathrm{M}$ of each primer, $1 \mathrm{U}$ Taq polymerase, and $20 \mathrm{ng}$ of template DNA. The amplification was performed with the following thermal program: $94{ }^{\circ} \mathrm{C}$ for $4 \mathrm{~min}$; followed by 36 cycles of denaturation at $95{ }^{\circ} \mathrm{C}$ for $50 \mathrm{~s}$, annealing at $50{ }^{\circ} \mathrm{C}$ for $40 \mathrm{~s}$, elongation at $72{ }^{\circ} \mathrm{C}$ for $2 \mathrm{~min}$; and extension at $72{ }^{\circ} \mathrm{C}$ for $5 \mathrm{~min}$. All PCR reactions were performed twice. The products were kept at $4{ }^{\circ} \mathrm{C}$.

\section{IRAP analysis}

PCR amplification was performed in a final reaction volume of $20 \mu \mathrm{L}$ containing $10 \times$ buffer, $800 \mathrm{mM}$ dNTPs, $0.3 \mathrm{nM}$ of each primer, $1.25 \mathrm{U}$ Taq polymerase, and $20 \mathrm{ng}$ of template DNA. The amplification was performed with the following thermal program: $94{ }^{\circ} \mathrm{C}$ for $4 \mathrm{~min}, 36{ }^{\circ} \mathrm{C}$ for $1 \mathrm{~min}, 72{ }^{\circ} \mathrm{C}$ for $2 \mathrm{~min}$; followed by 40 cycles of denaturation at $94{ }^{\circ} \mathrm{C}$ for $1 \mathrm{~min}$, annealing at $36^{\circ} \mathrm{C}$ for $1 \mathrm{~min}$, elongation at $72{ }^{\circ} \mathrm{C}$ for $2 \mathrm{~min}$; and extension at $94{ }^{\circ} \mathrm{C}$ for $4 \mathrm{~min}, 36{ }^{\circ} \mathrm{C}$ for $1 \mathrm{~min}, 72{ }^{\circ} \mathrm{C}$ for 2 min. All PCR reactions were performed twice. The products were kept at $4{ }^{\circ} \mathrm{C}$.

\section{Electrophoresis detection and genotypes of reaction products}

DNA amplification products for SCoT and IRAP markers were analyzed by electrophoresis in $1.80 \%$ agarose gels. The electrophoretic patterns of the products were recorded using a gel imaging system (Tanon 3500R, Shanghai, China). Genotypes were built based on different DNA band patterns on gels.

\section{Data analyses}

Data matrices of Inter-simple sequence repeat and start codon targeted polymorphic marker profiles were generated by scoring (1) for presence and (0) for absence of individual allele. Polymorphism information content (PIC) is a property value of a marker based on its allelic number and distribution frequency in a population. PIC for marker $i$ was calculated using PIC $=1-\Sigma P i^{2}$ according to Botstein et al. [3], where $P i$ is the allele frequency at locus $i$. Nei's genetic diversity index $(h)$ was 


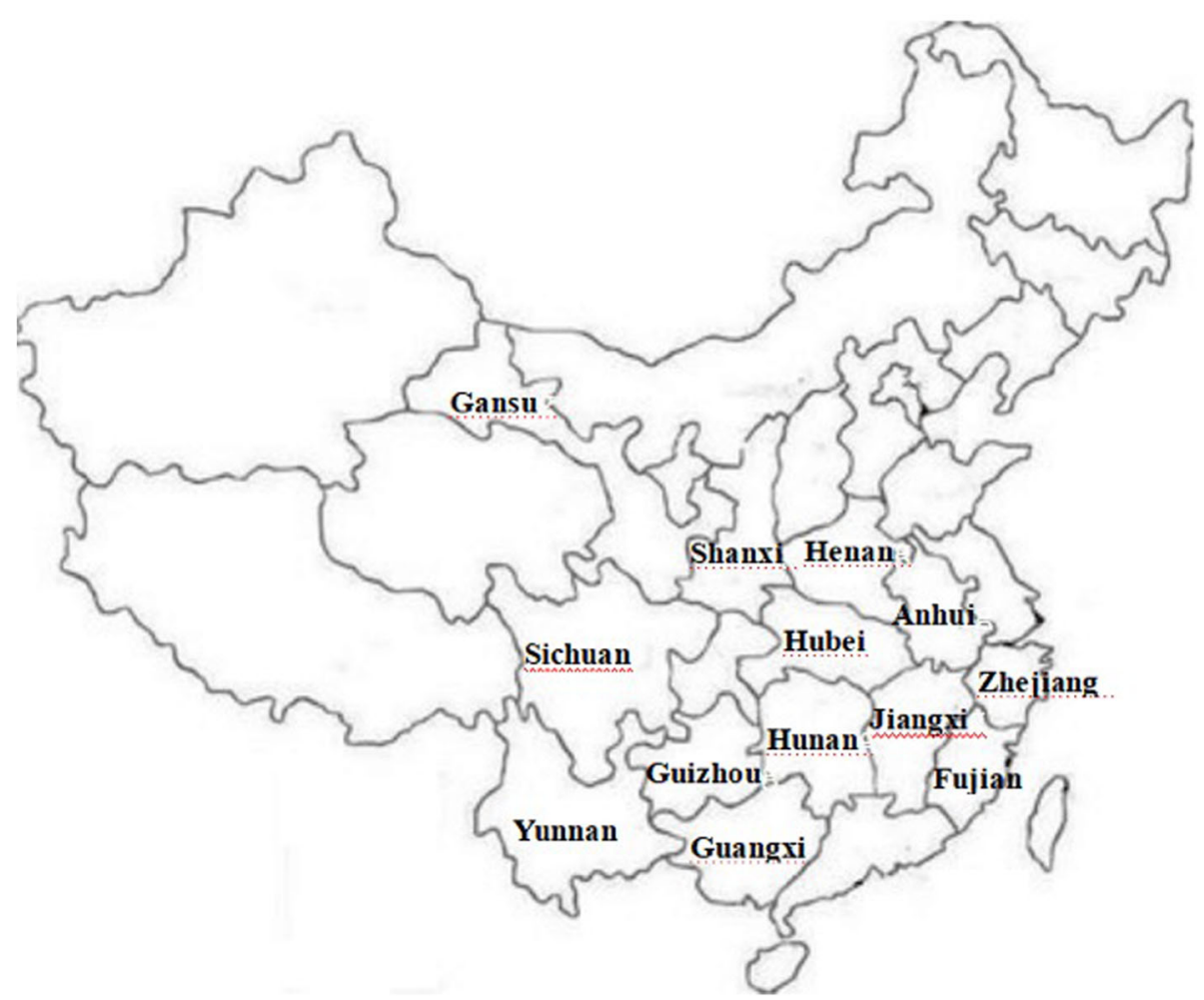

Fig. 7 Collecting sites for the Bletilla striata species in China are marked

calculated using POPGENE 1.31[19]. The resulting matrices were used to construct the dendrogram through unweighted pair-group method with arithmetic mean (UPGMA) using SAHN module. The cluster, cophenetic correlation and PCoA analysis was conducted by NTSYSpc software version 2.1. Analysis of molecular variance (AMOVA) was performed in order to determine the differences existent amongst and within population levels. F-statistics (Fst) was also calculated using Arlequin v. 3.01 (Miller 1998).

\section{Acknowledgements}

We thank professor Zhishan Ding for technical support.

\section{Funding}

This study was supported by the Study on Quality Guarantee System of Chinese Herbal Pieces in the State Administration of Traditional Chinese Medicine (No.201507002), National Natural Science Foundation of China (No.81503329) and Zhejiang Province Public Welfare Technology Application Research Project (2015C32084).

\section{Availability of data and materials}

The data that support the findings of this study are available from the corresponding author (Bo Jin) upon reasonable request.

\section{Authors' contributions}

$B J$ and ZD conceived and designed the study. YG, LZ, and HL performed the experiments. YG wrote the paper. YG, NC, and CG reviewed and edited the manuscript. All authors read and approved the manuscript.

Ethics approval and consent to participate Not applicable.

\section{Consent for publication}

All authors agree to publication.

\section{Competing interests}

The authors declare that they have no competing interests.

\section{Publisher's Note}

Springer Nature remains neutral with regard to jurisdictional claims in published maps and institutional affiliations.

\section{Author details}

${ }^{1}$ College of Life Science, Zhejiang Chinese Medical University, Hangzhou 310053, China. ${ }^{2}$ College of Medical Technology, Zhejiang Chinese Medical University, Hangzhou 310053, China.

Received: 21 July 2018 Accepted: 28 October 2018

Published online: 12 November 2018

\section{References}

1. Ahmad MG, Peter P, Zsolt P, Janos T. Efficiency of arbitrarily amplified dominant markers (SCOT, ISSR and RAPD) for diagnostic fingerprinting in tetraploid potato. Am J Pot Res. 2011;88:226-37.

2. Alikhani L, Rahmani M-S, Naghi S, Hedieh B, Abdollah KK. Genetic variability and structure of Quercus brantii assessed by ISSR, IRAP and SCoT markers. Gene. 2014;552:176-83.

3. Botstein D, White RL, Skolnick M, Davis RW. Construction of a genetic linkage map in man using restriction fragment length polymorphisms. AJHG. 1980:32:314-31.

4. Chinese Herbalism Editorial Board. Zhonghua Bencao. Shanghai: Shanghai Scientific \& Technical Publishers; 1999. p. 7803.

5. Collard BCY, Mackill DJ. Start codon targeted (SCOT) polymorphism: a simple, novel DNA marker technique for generating gene-targeted markers in plants. Plant Mol Biol Rep. 2009;27:86-93. 
6. Kalendar R, Grob T, Regina M, Suoniemi A, Schulman A. IRAP and REMAP: two new retrotransposon-based DNA fingerprinting techniques. Theor Appl Genet. 1999;98:704-11.

7. Lawler LJ. Ethnobotany of the orchidaceae. In: Arditti J, editor. Orchid Biology, vol. 3. America: Reviews and Perspectives. Cornell University Press, NY; 1984. p. 256.

8. Li Y, Liu YL, Cui CJ, Li XJ, Liang GJ, Peng J, Tian PPRAPD. Analysis of genetic diversity in Saccharina japonica germplasm resources. Biotechnol Bull. 2016; 32:151-8.

9. Li R, Wang ZZ. Research survey and countermeasure on resources utilization in stem tuber of Bletilla striata. Chin Tradit Herb Drugs. 2006;37:1751-5.

10. Milligan BG, Leebens-Mack J, Strand AE. Conservation genetics: beyond the maintenance of marker diversity. Mol Ecol. 1994;12:844-55.

11. Nakatsuji R, Hashida T, Matsumoto N, Tsuro M, Kubo N, Hirai M. Development of genomic and EST-SSR markers in radish (Raphanus sativus L.). Breed Sci. 2011;61:413-9.

12. Perry LM, Metzger J. Medicinal plants of east and Southeast Asia: attributed properties and uses. Cambridge: MIT Press; 1990. p. 168.

13. Rahmani M-S, Paula M, Pijut NS, Mona N. Genetic fidelity assessment of in vitro-regenerated plants of Albizia julibrissin using SCOT and IRAP fingerprinting. Biol Plant. 2015;51:407-19.

14. Shi J. Resources and medicinal utilization of Bletilla (orchidaceae). Hainan University: Dissertation; 2009.

15. Shi J, Luo YB, Song XQ. To Surve and analyze the market of Bletilla striata in China. Chiese Horti Culture Abstracts. 2010;8:48-50.

16. Sorkheh K, Nazanin A, Sezai E. Potential start codon targeted (SCOT) and inter-retrotransposon amplified polymorphism (IRAP) markers for evaluation of genetic diversity and conservation of wild Pistacia species population. Biochem Genet. 2016;54:368-87.

17. Wu JN. An illustrated Chinese Materia Medica. New York: Oxford University Press; 2005.

18. Wu YG, Guo QS, He JC, Lin YF, Luo LJ, Liu GD. Genetic diversity analysis among and within populations of Pogostemon cablin from China with ISSR and SRAP markers. Biochem Syst Ecol. 2010;38:63-72.

19. Yeh FC, Yang RC, Boyle TBJ, Ye ZH, Mao JX. "POPGENE, the user friendly shareware for population genetic analysis version1. 31," University of Alberta and Centre For International Forestry Research, vol. 28; 1999. p. 45-7.

20. Zhou TH, Li J, Ding JX, Yang H, Chen SL. SSR fingerprinting of Bletilla striata Rchb.f. Germplasm and its relatives or congeners. Acta bot. Boreal -OcidentSin. 2017;37:0673-81.

21. Zhang MB, Fan GQ, Chen JM, Chen P. Study on DNA isolation from polysaccharides-rich transgenic dendrobium. Mol Plant Breed. 2009;7:209-14.

22. Zhang YW, Jiang FS, Wang Y, Ding ZS. Present status and sustainable development of Rhizoma Bletillae industry. Chin Arch Tradit Chin Med. 2012;30:2264-7.

Ready to submit your research? Choose BMC and benefit from:

- fast, convenient online submission

- thorough peer review by experienced researchers in your field

- rapid publication on acceptance

- support for research data, including large and complex data types

- gold Open Access which fosters wider collaboration and increased citations

- maximum visibility for your research: over $100 \mathrm{M}$ website views per year

At $\mathrm{BMC}$, research is always in progress.

Learn more biomedcentral.com/submissions 